\title{
Psychosocial assessment and quality of life assessment in children with congenital heart in a developing country
}

\author{
Aly Abdel Mohsen, Mona Gamal Kassem and Manal A.-M. Antonios* (i)
}

\begin{abstract}
Background: Few studies have examined the clinical utility of a brief psychosocial screening questionnaire and assessing the health-related quality of life as part of routine care in a pediatric cardiology clinic.

Subject and methods: A cross-sectional study was conducted over 6 months duration involving 224 patients with congenital heart diseases (CHD) aged 4-18years and their parents to fulfill Pediatric Symptom Checklist (PSC) and Health related - Quality Of Life (HR-QOL) score. Statistical analysis of reliability of these scores among the studied population was carried using Cronbach's alpha value.

Results: The studied population with CHD, aged 4-18years with a mean \pm standard deviation of $99.48 \pm 43.37$ months. They were $54.5 \%$ males $(n=122)$ and $45.5 \%$ females $(n=102)$. Internalizing problems were identified by PSC in $12.95 \%$ of patients $(n=29)$, Cyanosis was found to be the only significant independent risk factor for developing internalizing defects $(p<0.001)$. Quality of school functioning was the most affected domain in HRQOL. While, the quality of social functioning remained good in the majority of cases. Cronbach's alpha value coefficient of PSC and HR-QOL scores were 0.846 and 0.900 respectively, reflecting good to excellent reliability of these scores within the studied population.
\end{abstract}

Conclusions: Children with CHD have increased need for psychosocial assessment for improvement of their quality of life.

Keywords: Psychosocial assessment, PSC, Quality of life, Congenital heart diseases

\section{Background}

Nowadays, $90 \%$ of newborns diagnosed with congenital heart diseases (CHD) live to adulthood [1]. As survival rates improved, psychosocial issues have emerged as a critical research area [2]. The question of how best to identify children and families who could benefit from psychology support is crucial, given the limited psychology resources [3]. Systematic psychosocial screening processes have been implemented in primary-care settings [4]. Jellinek et al [5] have created the Pediatric Symptom

\footnotetext{
*Correspondence: malakmanal@yahoo.com

Department of Pediatrics, Alexandria University, Faculty of Medicine,

El-Shatby Hospital Alexandria, Port Saiid Street El-Azarita District, Alexandria ZIP code: 21526, Egypt
}

Checklist (PSC) questionnaire to identify children with difficulties in psychosocial functioning, PSC is not a diagnostic tool, but indicates that children with positive results would benefit from further evaluation [6]. Moreover, the evaluation of Quality Of Life (QOL) provides a comprehensive description of the health of the individual in relation to physical, functional and psychosocial dysfunctions and is an important component in assessing the long-term impact of chronic conditions [7]. Health Related-quality of life (HR-QOL) tool is an assessment of how individual well-being may be affected over time by a disease or disability [8]. To date, studies on QOL in CHD patients reported contradictory findings: some studies reported poorer QOL related to cardiac instability and 
disease severity [9], while others concluded that CHD patients had better QOL than healthy people [10].

In developing countries, there is lack of interest in the psychosocial impact of chronic disease and its effect on QOL.

\section{Aims of the study}

This study aimed to assess the psychosocial aspect and quality of life of children with stable congenital heart disease and to check the validity of the screening tools used among the studied population.

\section{Methods}

A cross-sectional study was designed to screen pediatric patients with $\mathrm{CHD}$ coming for follow-up in the cardiology clinic of a tertiary care level hospital affiliated to a university in a developing country. Included patients aged 4-18years should have their diagnosis confirmed by a 10 year expert echo-cardiographer. Patients having associated other congenital malformations, genetic syndromes, or neurologic or mental handicaps were excluded. After explaining the benefit of the study to parents or care-givers of the patients, an informed written consent was obtained for the purpose of publication. After initial data entry, included cases were asked to fulfill the PSC [11], which consists of 35 questions some of them were addressed to the patient, others were addressed to the parents or caregivers because parents are often the first to notice a problem with the child's behavior or emotions even before the child himself. For each item a score of 0,1 , or 2 is provided, then a total score for all 35 items is calculated. The PSC score includes 3 domains of psychological assessment: attention, internalizing, and externalizing subscales. Each subscale consists of a set of questions that represent a tool of diagnosing the patient readiness to suffer from a psychiatric disturbance. An attention positive subscale points to possible attention deficit hyperactivity disorders, internalizing subscale positive refers to possible depression disorders, and finally externalizing subscale positive refers to possible conduct disorders. Then, the HR-QOL score [12] consisting of 23 questions divided into 4 main sections: problems with physical functioning (8 questions), problems with emotional, social, and school functioning ( 5 questions each). For each item, a score of $0-4$ is recoded. In the present study, patients aged $4-<8$ years, their HR- QOL score was answered by the parents or caregivers only, patients aged 8-12 years were involved in the assessment along with their parents and they discussed together before choosing the appropriate scores. Finally, patients aged 13-18 years answered the HR-QOL score alone with no interference from their parents. For each section, results were stratified into poor, fair, good, and excellent according to the interpretation of the QOL score: $<25 \%, 25-50 \%, 50-75 \%$, and $>75 \%$, respectively.

A sample size of 220 patients was calculated to evaluate PSC, HR-QOL scores with a statistical power of $80 \%$ and statistical significance less than 5\% [13].

\section{Statistical consideration}

Statistical analysis used SPSS (Statistical Package for Social Science) program (version 21), where data was described using minimum, maximum, mean, standard deviation and $95 \%$ Confidence Interval (CI) of the mean, median and Inter-Quartile Range (IQR). KolmogorovSmirnov test of normality was carried for each variable. Comparisons were carried out between the studied groups using independent sample $\mathrm{t}$ test. Monte-carlo and Yate's (continuity) correction were carried out when indicated. Comparisons were carried out between two studied independent not-normally distributed subgroups using Mann-Whitney $U$ test. The binary logistic model is used to estimate the probability of a binary response based on one or more predictor (or independent) variables. The calibration was assessed by directly comparing the observed and customized predicted positive internalizing defect across subcategories of risk. We employed the Hosmer-Lemeshow goodness-of-fit test, where a $p$ value $>0.10$ indicates acceptable calibration. Cronbach's (alpha) was used to estimate the reliability of the scores used in the study.

\section{Ethical statement}

All procedures performed in the current study were in accordance with the 1964 Helsinki Declaration and its amendments. The University ethical committee approved the study design on March 2018 (IRB:00007555FWA:00018699, serial:0105443).

\section{Results}

The current study screened 339 patients visiting the outpatient clinic, Fig. 1 shows the Reporting of Studies Conducted using Observational Routinely-Collected health Data (RECORD) recruitment strategy. Table 1 shows the demographic and clinical data of the studied population $(n=224)$ with a median age of 86 months and interquartile range of (66-116months). There were $54.46 \%$ $(n=122)$ male patients versus $45.54 \%(n=102)$ female patients. The PSC screening revealed negative results concerning both attention and externalizing subscales and positive cases recorded to have internalizing problems only (12.95\%, $n=29$ patients) which are prone to develop depressive disorders. Table 2 shows that $10.27 \%$ (23 patients responded to the internalizing subscale positively, while $6.7 \%$ ( 15 patients) were retrieved as positive internalizing subscale due to their parents responses to 
Total number of patients with congenital heart screened $(n=339)$

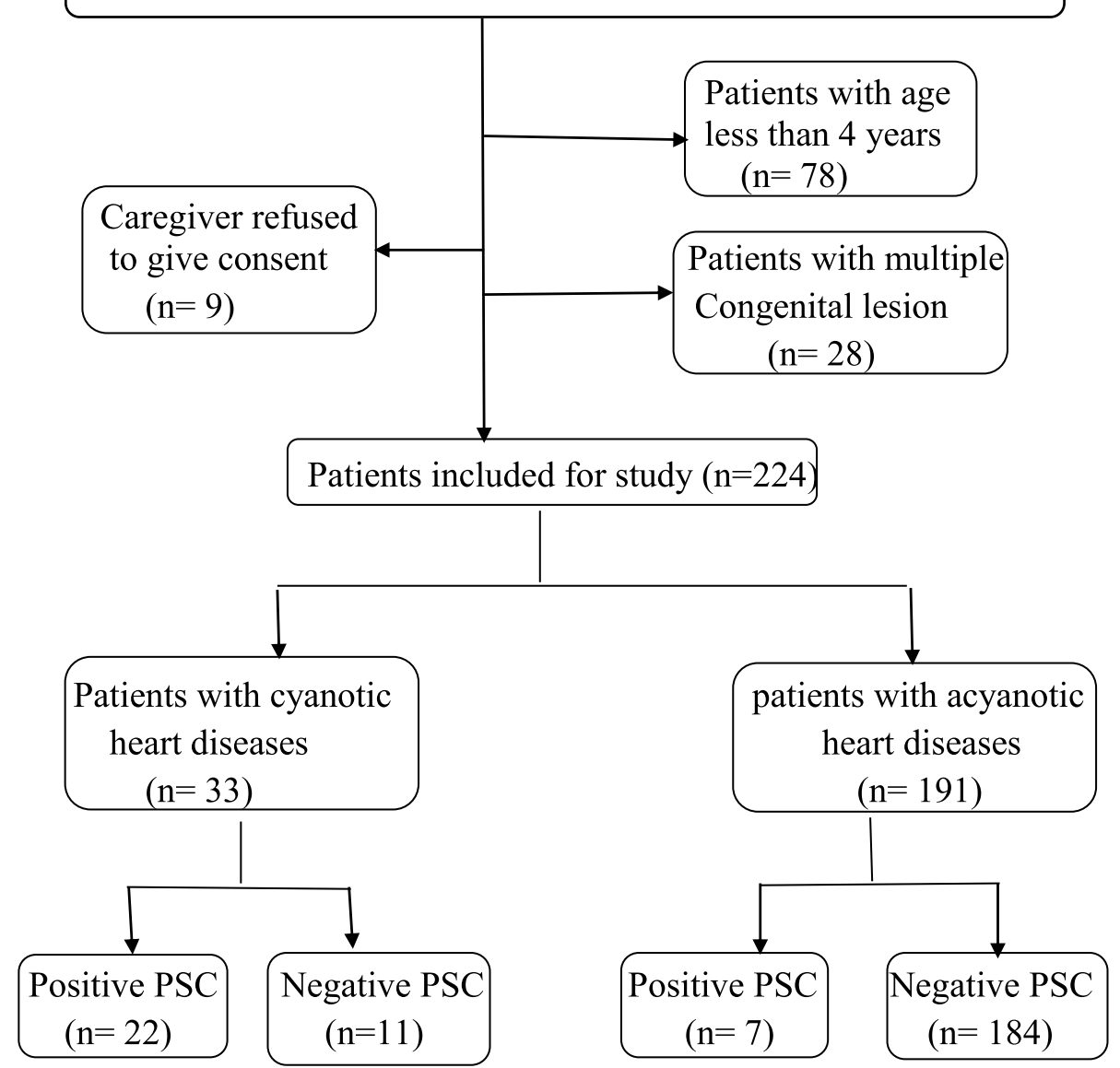

Fig. 1 RECORD of the strategy of recruitment of the studied population

the PSC items. This means that $2.68 \%(n=6)$ patients responded negatively to the PSC score while their parents responded positively. $(4 \%(n=9)$ patients and their parents confirmed having psychosocial defect, while $6.25 \%(n=14)$ patients reported having problems while their parents were not aware of their kids' sufferings).

Table 3 shows results of comparison between patients with positive total internalizing subscale of the PSC score compared to those with negative results. Significant risk factors were entered into a multiple logistic regression modeling shown in Table 4. Cyanosis was found to be the only significant independent risk factor for developing internalizing defects in the studied population $(p<0.001)$. Patients with cyanotic heart diseases were four folds at higher risk of developing internalization defects and depressive disorders compared to patients with acyanotic heart diseases.

Table 5 shows results of HR-QOL scores stratified into 4 domains: physical, emotional, social, and school functioning. Results revealed that the quality of school functioning was the most affected domain with $4.46 \%$ $(n=10)$ of patients being poor. While, the quality of social functioning was the least affected with $85.27 \%$ ( $n=191$ patients) having excellent functioning capacities.

Table 6 shows the total Cronbach's alpha value of the PSC and HR-QOL scores among the studied population. Cronbach's alpha coefficient value of 0.846 reflects good reliability of the PSC score. While, Cronbach's alpha coefficient of 0.900 reflects excellent reliability of the HRQOL score.

\section{Discussion}

Extensive research has documented neuro-developmental and psycho-social challenges among children and adolescents with CHD, prompting a scientific statement from the American Heart Association recommending periodic developmental surveillance, screening, evaluation, and re-evaluation [14]. The current study included 224 patients with CHD, aged 4-18 years with a mean \pm standard deviation of $99.48 \pm 43.37$ months. They 
Table 1 Demographic data of the studied population

\begin{tabular}{|c|c|c|}
\hline & $n=224$ & percent \\
\hline \multicolumn{3}{|l|}{ Age at the study (months) } \\
\hline Min-Max & $48.00-223.00$ & 100.00 \\
\hline Mean (Std. deviation) & $99.48(43.37)$ & \\
\hline Median (IQR) & $86.00(66-116)$ & \\
\hline \multicolumn{3}{|l|}{ Gender } \\
\hline Male & 122 & 54.46 \\
\hline Female & 102 & 45.54 \\
\hline Cyanotic heart lesions $^{a}$ & 33 & 14.73 \\
\hline Fallot tetralogy & 16 & 7.14 \\
\hline TGA & 10 & 4.46 \\
\hline Ebstein anomaly & 1 & 0.45 \\
\hline Double outlet right ventricle & 4 & 1.79 \\
\hline Double inlet left ventricle & 1 & 0.45 \\
\hline Tricuspid atresia & 1 & 0.45 \\
\hline Acyanotic heart lesions & 191 & 85.27 \\
\hline PS mild & 3 & 1.34 \\
\hline moderate & 2 & 0.89 \\
\hline severe & 3 & 1.34 \\
\hline Bicuspid aortic valve & 1 & 0.45 \\
\hline AS moderate & 1 & 0.45 \\
\hline Severe & 1 & 0.45 \\
\hline Coarctation of aorta & 3 & 1.34 \\
\hline Subaortic membrane & 18 & 8.04 \\
\hline VSD small & 29 & 12.95 \\
\hline Large & 63 & 28.13 \\
\hline ASD small & 14 & 6.25 \\
\hline Large & 41 & 18.30 \\
\hline MVP & 19 & 8.48 \\
\hline \multicolumn{3}{|l|}{ PDA } \\
\hline Tricuspid regurge mild & 17 & 7.59 \\
\hline moderate & 3 & 1.34 \\
\hline severe & 2 & .89 \\
\hline \multirow[t]{2}{*}{ Dextrocardia } & 4 & 1.79 \\
\hline & 4 & 1.79 \\
\hline Cyanosis & 33 & 14.73 \\
\hline Controlled heart failure & 44 & 19.6 \\
\hline \multicolumn{3}{|l|}{ Cardiac operation } \\
\hline palliative operation & 22 & 9.82 \\
\hline Corrective operation & 98 & 43.75 \\
\hline Complication & 1 & 0.45 \\
\hline
\end{tabular}

TGA Transposition of great arteries PS pulmonary stenosis AS Aortic stenosis $V S D$ : Ventricular septal defect ASD Atrial septal defect MVP mitral valve prolapse $P D A$ Patent ductus arteriosus ${ }^{\text {a }}$ : One patient may have more than one diagnosis

were $54.5 \%$ males $(n=122)$ and $45.5 \%$ females $(n=102)$. The PSC score implemented in this study revealed no cases with attention problems or externalizing defects. The only positive cases were found to have internalizing impairment $(12.95 \%, n=29)$. Interestingly, the PSC
Table 2 Results of Pediatric Symptom Checklist

\begin{tabular}{lll}
\hline Total internalizing subscale results & $\mathbf{n}$ & Percent \\
\hline Negative & 195 & 87.05 \\
Positive & 29 & 12.95 \\
Total & 224 & 100.00 \\
Parents' internalizing subscale items & & \\
$\quad$ Negative & 209 & 93.30 \\
$\quad$ Positive & 15 & 6.70 \\
$\quad$ Total & 224 & 100.00 \\
Patients' internalizing subscale items & & \\
$\quad$ Negative & 201 & 89.73 \\
$\quad$ Positive & 23 & 10.27 \\
$\quad$ Total & 224 & 100.00 \\
\hline
\end{tabular}

Table 3 Comparison between patients with negative and positive results for the total internalizing subscale of PSC as regards variable risk factors

\begin{tabular}{|c|c|c|c|}
\hline \multirow[t]{2}{*}{ Risk factors } & \multicolumn{2}{|c|}{$\begin{array}{l}\text { Internalizing subscale } \\
\text { results }\end{array}$} & \multirow[t]{2}{*}{$\begin{array}{l}\text { Test of significance } \\
\text { ( } p \text { value) }\end{array}$} \\
\hline & $\begin{array}{l}\text { Negative } \\
(n=195)\end{array}$ & $\begin{array}{l}\text { Positive } \\
(n=29)\end{array}$ & \\
\hline \multicolumn{4}{|c|}{ Age at study (months) } \\
\hline Mean $\pm S D$ & $100.73 \pm 44.82$ & $91.07 \pm 31.33$ & $Z_{(M W)}=0.628$ \\
\hline Median (IQR) & $86(66-116)$ & $80(65-102)$ & $p=0.530$ \\
\hline \multicolumn{4}{|l|}{ Gender } \\
\hline Male & $107(47.8 \%)$ & $15(6.69 \%)$ & $X_{(Y)(d f=1)}^{2}=0.014$ \\
\hline Female & $88(39.28 \%)$ & $14(6.25 \%)$ & $\mathrm{p}_{(Y)}=0.906$ \\
\hline \multicolumn{4}{|c|}{ Cardiac operation } \\
\hline Not operated & $93(41.52 \%)$ & $10(4.46 \%)$ & \\
\hline $\begin{array}{l}\text { Palliative } \\
\text { surgery }\end{array}$ & $10(4.46 \%)$ & $12(5.36 \%)$ & $X_{(d f=3)}^{2}=37.815$ \\
\hline $\begin{array}{l}\text { Corrective } \\
\text { surgery }\end{array}$ & $91(40.62 \%)$ & $7(3.125 \%)$ & $\mathrm{p}_{(\mathrm{MC})}=0.000^{*}$ \\
\hline complications & $0(0.0 \%)$ & $1(0.45 \%)$ & \\
\hline \multicolumn{4}{|l|}{ Heart failure } \\
\hline Negative & $164(73.2 \%)$ & $16(7.14 \%)$ & $X_{(Y)(d f=1)}^{2}=11.616$ \\
\hline Controlled & $31(13.84 \%)$ & $13(5.8 \%)$ & $\mathrm{p}_{(Y)}=0.001^{*}$ \\
\hline \multicolumn{4}{|l|}{ Cyanosis } \\
\hline Negative & $184(82.1 \%)$ & $7(3.125 \%)$ & $X_{(Y)(d f=1)}^{2}=93.587$ \\
\hline Positive & $11(4.91 \%)$ & $22(9.82 \%)$ & $P_{(Y)}=0.000^{*}$ \\
\hline
\end{tabular}

$S D$ Standard deviation IQR Interquartile range $M W$ Mann-Whitney $\mathrm{U}$ test $Y$ Yate (continuity) correction MC Monte Carlo test *: Statistically significant $(p<0.05)$

items answered by the patients revealed only 23 patients with internalizing deficit. Considering the answers of parents' items in the PSC, 6 more patients were identified. The internalizing positive cases are more prone to develop anxiety or depressive disorders, positive cases were referred by the researcher to get psychological 
Table 4 Multiple logistic regression of the significant risk factors for developing internalizing problems

\begin{tabular}{|c|c|c|c|c|c|c|c|}
\hline \multirow[t]{2}{*}{ Variables } & \multirow[t]{2}{*}{ B } & \multirow[t]{2}{*}{$\operatorname{Exp}(B)$} & \multirow[t]{2}{*}{ S.E } & \multirow[t]{2}{*}{ OR } & \multicolumn{2}{|l|}{$95 \% \mathrm{Cl}$} & \multirow[t]{2}{*}{ Sig } \\
\hline & & & & & Lower & Upper & \\
\hline Constant & -3.557 & 0.029 & 0.618 & 33.142 & & & \\
\hline Palliative surgery & -1.006 & 0.366 & 0.979 & 1.057 & 0.054 & 2.489 & 0.304 \\
\hline Corrective surgery & 0.356 & 1.430 & 0.771 & 0.215 & 0.315 & 6.481 & 0.643 \\
\hline Complication & -18.293 & 0.000 & $40,192.97$ & 0.000 & 0.000 & NA & 1.000 \\
\hline Heart failure & 0.647 & 1.910 & 0.690 & 0.879 & 0.494 & 7.386 & 0.348 \\
\hline Cyanosis & 4.641 & 103.649 & 0.902 & 26.476 & 17.694 & 607.165 & $0.000^{*}$ \\
\hline
\end{tabular}

$O R$ Odds ratio $C l$ Confidence interval NA not applicable due to low event rate ${ }^{*}$ : statistically significant $p=0.000$

The model was well calibrated (Hosmer - Lemeshow chi-square: $0.437, p=0.979$ )

Table 5 Results of Quality of Life scoring assessment

\begin{tabular}{lll}
\hline Physical_functioning_problems & $\mathbf{n}$ & Percent \\
\hline Fair (>25-50\%) & 9 & 4.02 \\
Good (>50-75\%) & 27 & 12.05 \\
Excellent (> 75-100\%) & 188 & 83.93 \\
Total & 224 & 100.00 \\
Emotional functioning problems & & \\
$\quad$ Fair (>25-50\%) & 10 & 4.46 \\
Good (>50-75\%) & 76 & 33.93 \\
Excellent (>75-100\%) & 138 & 61.61 \\
Total & 224 & 100.00 \\
Social functioning problems & & \\
Fair (>25-50\%) & 6 & 2.68 \\
Good (>50-75\%) & 27 & 12.05 \\
Excellent (>75-100\%) & 191 & 85.27 \\
Total & 224 & 100.00 \\
School functioning problems & & \\
Poor (0-25\%) & 10 & 4.46 \\
Fair (>25-50\%) & 22 & 9.82 \\
Good (>50-75\%) & 46 & 20.54 \\
Excellent (> 75-100\%) & 146 & 65.18 \\
Total & 224 & 100.00 \\
\hline
\end{tabular}

Table 6 Total Cronbach's alpha of Pediatric Symptom Checklist and Quality of Life scores

\begin{tabular}{llll}
\hline Scores & Item number & Cronbach's alpha & $\begin{array}{l}\text { Cronbach's alpha } \\
\text { on standardized } \\
\text { items }\end{array}$ \\
\hline PSC & 35 & 0.846 & 0.829 \\
QOL & 23 & 0.900 & 0.893 \\
\hline
\end{tabular}

PSC Pediatric Symptom Checklist QOL Quality Of Life

assessment and proper aid from a specialist. Consistent with the results of the present study, Latal et al [15] in their systematic review stated that psychological difficulties consisted predominantly of internalizing symptoms as retrieved from six studies, while three studies only observed significant externalizing symptoms.

Assessment of possible risk factors related to positive PSC cases showed that surgical interference, heart failure with prolonged treatment, presence of cyanosis were identified statistically significant $(p<0.001$, $p=0.001, \mathrm{p}<0.001$ respectively). While age and gender were not statistically proven as risk factors $(p=0.530$, $p=0.906$ respectively). Cyanosis was found to be the only significant independent predictor of developing internalizing deficit by multiple logistic regression modeling $(\mathrm{p}<0.001)$. Comparable to the current study, Areias et al. [16], stated that patients submitted to surgery had higher scores in PSC, namely internalization subscale $(p=0.007)$, externalization subscale $(p=0.024)$, and attitude subscale $(p=0.011)$. Moreover, relatives of their patients referred more to internalization defects $(p=0.006)$ for the complex forms of CHD and those having physical limitations $(p=0.027)$. Special emphasis on cyanosis was observed by Latal et al [15] in their systematic review; they found that rates of psychiatric disorders for children with surgically corrected transposition of great arteries and children with severe cyanotic defects ranged between 19 and 46\%. In line with these findings, parents of children with cyanosis or reduced physical capacity reported psychological maladjustment especially following surgery as reported by Gupta et al [17] and Bjornstad et al. [18]

Identification of the child with significantly impaired QOL may have the greatest clinical potential for improving outcomes of children with heart disease. Results of HR-QOL score in the current study showed that the majority of studied patients had excellent quality of life as regards the four domains: physical, emotional, social, and school functioning $(83.93 \%, 61.61 \%, 85.27 \%$, and $65.18 \%$ respectively). The worse physical functioning reported was fair in $4.02 \%(n=9)$, the worse emotional functioning 
was fair in $4.46 \%(n=10)$, social functioning was fair in $2.68 \%(n=6)$. The domain most affected was the school performance being poor in $4.46 \%(\mathrm{n}=10)$, and fair in $9.82 \%(n=22)$ of the studied patients. These results are in accordance with many other researches in literature. Krol et al [19] stated that although significantly lower than the scores of healthy children on several domains, yet mean health-related quality of life scores of children with CHD remained relatively good. Moons et al [9] stated that $78.1 \%$ were clustered as having a good QOL, $20.1 \%$ had moderate QOL, and only $1.8 \%(n=11)$ had poor QOL within a study of 612 adults with CHD. Many studies confirmed the poorer psychological well-being and QOL in CHD patients compared to healthy controls [20,21]. Uzark et al [22] concluded that comparison of the mean subscale scores for physical, emotional, social, and school QOL revealed that children with CHD were most different than norms especially school functioning scores $(p<0.001)$. Even though, they added that the majority of these children had a good QOL as perceived by themselves and their parents. The strong religious believes together with the familial consolidation in the setting of the current study helped children and their families to accept and better deal with their suffering as they conceived the disease as "the will of God". This statement was recorded repeatedly by many families while performing the study. This explains why despite of the low to moderate socio-economic class of the studied population, yet the prevalence of psycho-social impairment and hence the quality of life were found comparable to that recorded in well - developed centers.

The results of the present study showed that measures of internal consistency were high for the two metrics used in the study. The total Cronbach's alpha of PSC $(\alpha=0.846)$ which refers to it as a good tool of psychosocial assessment among the studied population. While, the total Cronbach's alpha for the HR-QOL was estimated to be $(\alpha=0.900)$ and this refers to an excellent tool of assessment of quality of life among the studied cases. The PSC have been widely used for research and have demonstrated sound psychometric properties. In a huge study by Gardner et al [4] that involved 18.045 patients within a primary care setting, PSC demonstrated good overall internal consistency $(\alpha=0.89)$ very comparable to the results of the current study. The PSC was also found to have good sensitivity and specificity when compared to similar well validated measures [23]. The HR-QOL tool developed by WHO is more widely valid and reliable psychometric analysis with excellent internal consistency in the study by DeSmedt et al. [24], Cronbach $\alpha$ was found to be 0.92 , again very close to the current results. This was proved to be a better tool of analysis if compared to a specific cardiac disease related QOL score developed by
Leiden University Medical Centre which reported a questionable reliability. $(\alpha=0.63)$ [19]

The PSC and HR-QOL scores proved to be effective and valuable instruments for the evaluation of patients with CHD given the increasing number of survivors. Recommendation from previous results suggests to combine both scores for screening children with psycho-social deficit and further detect those with poor quality of life. Applying one tool of screening would probably be less effective in detecting CHD patients in need for psychological support. This goes in parallel with Struemph et al [25] who concluded that PSC as a psychosocial screening tool could not detect impairments in executive, behavioral, social, cognitive and emotional adjustment. These domains are well covered by WHO - HR/QOL tool. So, the combined use of PSC and HR-QOL tools provides better insight into knowledge gaps or unrecognized psychosocial needs.

This study was not without limitations. First, although the size of the studied cases was large enough to produce sufficient power analysis, larger groups could contribute to generalizability of study results. Second, a multicenter collaboration is a means of increasing the number of participants and further expanding knowledge and understanding of the emotional and psychosocial aspect of heart diseases. The third weakness of the study is the potential sample bias because studied patients were recruited from cardiology outpatient clinic and this cohort could not represent the whole CHD population. It is unknown whether patients not receiving specialized care have better or poorer psycho-social functioning. Finally, patient functional status was quantified by subjective rather than objective assessment in view of the age of the studied group whether too young to understand and decide scores, or adolescent age which is basically a time of intense psychological changes and instability even among healthy individuals. So, results of these scores should be interpreted with lot of caution of misleading.

\section{Conclusions}

This study bears important implications for implementing psychosocial screening tools as a routine work-up within the cardiology out-patient clinic. This systematic screening could result in increased identification of patient in need for psychology specialist help in order to help them improve their quality of life.

\section{Acknowledgements \\ Not applicable.}

\section{Authors' contributions}

Aly Abdel-Mohsen was responsible for data analysis and revision of the manuscript. Mona Gamal Kassem - was responsible for protocol development, data collection. Manal A-M Antonios was responsible for the idea of the research, protocol development, data analysis and writing of the manuscript. The 
corresponding author has full access to data and has the right to publish such data. The author(s) read and approved the final manuscript.

\section{Funding}

All authors declare that they did not receive any financial support.

\section{Availability of data and materials}

All raw data and materials are available upon request from the corresponding author via an email.

\section{Declarations}

\section{Ethics approval and consent to participate}

All procedures performed in the current study were in accordance with the 1964 Helsinki Declaration and its amendments. The University ethical committee approved the study design on March 2018 (IRB:00007555-FWA:00018699, serial:0105443). After explaining the benefit of the study to parents or caregivers of the patients, a consent to participate in the study was obtained.

\section{Consent for publication}

An informed written consent was obtained for the purpose of publication.

\section{Competing interests}

All authors of this article declare no conflict of interest.

Received: 3 August 2021 Accepted: 3 October 2021

Published online: 08 November 2021

\section{References}

1. Apers S, Luyckx K, Rassart J et al (2013) Sense of coherence is a predictor of perceived health in adolescents with congenital heart disease: a crosslagged prospective study. Int J Nurs Stud 50:776-785

2. Marelli AJ, Mackie AS, Ionescu-Ittu R et al (2007) Congenital heart disease in the general population: changing prevalence and age distribution. Circulation 115:163-172

3. Hearps SJ, McCarthy MC, Muscara F et al (2014) Psychosocial risk in families of infants undergoing surgery for a serious congenital heart disease. Cardiol Young 24:632-639

4. Gardner W, Lucas A, Kolko DJ et al (2007) Comparison of the PSC-17 and alternative mental health screens in at-risk primary care sample. J Am Acad Child Adolesc Psychiatry 46:611-618

5. Jellinek M, Evans N, Knight RB (1979) Use of a behavior checklist on a pediatric inpatient unit. J Pediatr 94(1):156-158

6. Hacker KA, Myagmarjav E, Harris V et al (2006) Mental health screening in pediatric practice: factors related to positive screens and the contribution of parental/personal concern. Pediatrics 118:1896-1906

7. Goldbeck L, Melches J (2005) Quality of life in families of children with congenital heart disease. Qual Life Res 14:1915-1924

8. Burckhardt CS, Anderson KL (2003) The quality of life scale: reliability, validity, and utilization. Health Qual Life Outcomes 1:60-66

9. Moons P, Van Deyk K, Marquet K et al (2009) Profile of adults with congenital heart disease having a good, moderate, or poor quality of life : a cluster analytic study. Eur J Cardivasc Nurs 8:151-157
10. Fekkes M, Kamphuis RP, Ottenkamp J et al (2001) Health-related quality of life in young adults with minor congenital heart disease. Psychol Health $16: 239-250$

11. Jellinek MS, Murphy JM, Robinson J et al (2002) Pediatric symptom checklist: screening school-age children for psychosocial dysfunction. J Pediatr 112(2):20-22

12. Varni JW, Seid M, Kurtin PS (2001) Peds QL 4.0: reliability and validity of the pediatric quality of life inventory version 4.0 generic core scales in healthy and patient populations. Med Care 39:800-812

13. Pannucci CJ, Wilkins EG (2010) Identifying and avoiding bias in research. Plast Reconstr Surg 126(2):619-625

14. Marino BS, Lipkin PH, Newburger JW et al (2012) Neurodevelopmental outcomes in children with congenital heart disease: evaluation and management. A scientific statement from the American heart association. Circulation 126:1143-1172

15. Latal B, Helfricht S, Fischer JE et al (2009) Psychological adjustment and quality of life in children and adolescents following open heart surgery for congenital heart disease: a systematic review. BMC Pediatr 9(6):1471-1481

16. Areias ME, Pinto Cl, Vieira PF et al (2013) Long term psychosocial outcomes of congenital heart disease in adolescents and young adults. Transpl Pediatr 2(3):90-98

17. Gupta S, Giuffre RM, Crawford S et al (1998) Covert fears, anxiety and depression in congenital heart disease. Cardiol Young 8:491-499

18. Bjonstad PG, Spurkland I, Lindberg HL (1995) The impact of severe congenital heart disease on physical and psychological functioning in adolescents. Cardiol Young 5:56-62

19. Krol Y, Grootenhuis MA, DestrEe-Vonk A et al (2003) Health related quality of life in children with congenital heart disease. Psychol Health 18(2):251-260

20. Rose M, Köhler K, Köhler F et al (2005) Determinants of the quality of life of patients with congenital heart disease. Qual Life Res 14:35-43

21. Spijkerboer AW, Utens EM, DeKoning WB et al (2006) Health-related quality of life in children and adolescents after invasive treatment for congenital heart disease. Qual Life Res 15:663-673

22. Uzark K, Jones K, Slusher J et al (2008) Quality of life in children with heart disease as perceived by children and parents. Pediatrics 121(5):e1060-e1067

23. Gardner W, Murphy M, Childs G et al (1999) The PSC a brief pediatric symptom checklist with psychological problem subscales. A report from PROS and ASPN. Ambul Child Health 5:225-236

24. DeSmedt D, Clays E, Höfer S et al (2016) Validity and reliability of the heart $\mathrm{QOL}$ questionnaire in a large sample of stable coronary patients. Eur J Prev Cardiol 23(7):714-721

25. Struemph KL, Barhight LR, Thacker D et al (2016) Systematic psychosocial screening in a paediatric cardiology clinic: clinical utility of the paediatric symptom checklist 17. Cardiol Young 26(6):1130-1136

\section{Publisher's Note}

Springer Nature remains neutral with regard to jurisdictional claims in published maps and institutional affiliations.

\section{Submit your manuscript to a SpringerOpen ${ }^{\circ}$ journal and benefit from:}

- Convenient online submission

- Rigorous peer review

- Open access: articles freely available online

- High visibility within the field

- Retaining the copyright to your article

Submit your next manuscript at $\boldsymbol{\nabla}$ springeropen.com 